\title{
Magnetization for Burgers' Fluid Subject to Convective Heating and Heterogeneous-Homogeneous Reactions
}

\author{
Kotha Gangadhar, ${ }^{1}$ Manda Aruna Kumari, ${ }^{1}$ M. Venkata Subba Rao, ${ }^{2}$ Khaled Alnefaie, ${ }^{3}$ \\ Ilyas Khan $\mathbb{D}^{4}$, and Mulugeta Andualem $\mathbb{D}^{5}$ \\ ${ }^{1}$ Department of Mathematics, Acharya Nagarjuna University Ongole Campus, Ongole, Andhra Pradesh 523001, India \\ ${ }^{2}$ Division of Mathematics, Department of Sciences and Humanities, Vignan's Foundation for Science, Technology and Research, \\ Vadlamudi, Andhra Pradesh 522 213, India \\ ${ }^{3}$ Department of Mechanical Engineering, College of Engineering, King Abdulaziz University, P.O. Box 80248, \\ Jeddah 21589, Saudi Arabia \\ ${ }^{4}$ Department of Mathematics, College of Science Al-Zulfi, Majmaah University, Al-Majmaah 11952, Saudi Arabia \\ ${ }^{5}$ Department of Mathematics, Bonga University, Bonga, Ethiopia
}

Correspondence should be addressed to Ilyas Khan; i.said@mu.edu.sa and Mulugeta Andualem; mulugetaandualem4@gmail.com

Received 28 October 2021; Revised 24 December 2021; Accepted 19 January 2022; Published 14 February 2022

Academic Editor: Xiantao Jiang

Copyright (c) 2022 Kotha Gangadhar et al. This is an open access article distributed under the Creative Commons Attribution License, which permits unrestricted use, distribution, and reproduction in any medium, provided the original work is properly cited.

\begin{abstract}
The flow of Burgers' fluid in the magnetic field new mathematical modeling is introduced in this article which is heated convectively and maintained. The thermal energy transport aspects are examined by employing the space- and temperaturerelated heat source. In the present investigation, the homogeneous-heterogeneous reactions will present the features of scrutiny of the fluid concentration. For the purpose of dimensionless similarity transformations, ordinary differential equations (ODEs) are utilized practically. Developed ODEs are solved by introducing the concepts of Runge-Kutta-Fehlberg's fourth-fifth method. The graphs show the pertinent outcome. The relaxation time parameter is exhibited by diminishing the thermal distribution of Burgers' fluid property, and this will depend on the relaxation time factor. Biot number and retardation time factor behaviors are analyzed by opposing the behavior of the material factor of Burgers' fluid. The response of homogeneous strength is deteriorated by the concentration rate of the fluid, and this will augment the data using the heterogeneous response with greater magnitude. By using already published studies, it is investigated that the present investigation is validated.
\end{abstract}

\section{Introduction}

Fundamentally, Burgers' liquid is a non-Newtonian liquid. The non-Newtonian substance has critical significance and parcel of actual applications because of which specialists and designers are giving their consideration towards this subject. A large portion of the materials utilized in the petrochemical, biochemical, and geophysical impacts are nonNewtonian. On account of their various attributes, a few sorts of non-Newtonian models have been set up. These materials are present as differential, fundamental, and ratetype materials. Scientists accomplished a momentous consideration on discrepancy and rate-type classification of models. The Burgers' liquid model is reflected as the viscoelastic rate-type liquid model which is an extensively evolved model. Burgers' model has a propensity to rearrange pressure unwinding of a few polymeric liquids. Plentiful examinations on non-Newtonian tools can be established; for example, Dong et al. [1] developed an analysis between one-dimensional non-Fourier heat conduction and nonNewtonian flow in nanosystems. Mehryan et al. [2] examined melting heat transfer of power-law fluid in nano-enhanced $n$-octadecane-mesoporous silica $\left(\mathrm{MPSiO}_{2}\right)$. HazeriMahmel et al. [3] examined a three-dimensional analysis of 
forced convection of Newtonian and non-Newtonian nanofluids through a horizontal pipe using single- and twophase models.

Ajeeb et al. [4] studied forced convection heat transfer of non-Newtonian MWCNT nanofluids in microchannels under laminar flow. Yadav and Kumar [5] applied an inclined magnetic field effect to study entropy production of nonmiscible Newtonian and micropolar fluid in a rectangular type geometry. Esfe et al. [6] provided a detailed analysis of the rheological behavior of MWCNT- $\mathrm{Al}_{2} \mathrm{O}_{3}(10$ : 90)/5W50 hybrid non-Newtonian nanofluid with viscosity consideration. Saleem et al. [7] and Vishal et al. [8] also studied non-Newtonian fluids with different aspects and conditions. Ali et al. [9] examined G-jitter impact on MHD non-Newtonian fluid over an inclined surface using finite element discretization. Subhas Abel et al. [10] examined MHD flow and heat transfer for the upper-convected Maxwell fluid past a stretching sheet. Waqas et al. [11] examined an Oldroyd-B nanoliquid with heat generation.

At first, Maxwell, in 1866, presented the viscoelastic liquid for clarifying the conduct of liquids such as air, instead of polymeric fluids. Burgers [12] introduced a one-dimensional rate kind of liquid model in 1939 that covers the onedimensional Maxwell model [13] as an extraordinary case to clarify the viscoelastic conduct of liquid materials. Blacktop (asphalt, tarmacadam, or other black material used for surfacing roads) [14-17] gave a discussion about the utilization of Burgers' liquid model to portray the attributes of viscoelastic kind of liquids.

Shehzad et al. [18] concentrated on the convective warmth and mass limit conditions in the MHD stream of nanofluid. Zuo et al. [19] introduced the Taguchi trial plan and dark social investigation to assess the impacts of hydrogen/air proportionality proportion, channel speed, delta temperature, divider warm conductivity, divider emissivity, and convective heat transfer coefficient of the external divider on burning productivity of hydrogen/air premixed fire in a miniature tube-shaped combustor. Madhavi et al. [20] concentrated on Darcy stream in viscoelastic convection from a slanted plate as a reenactment of electroconductive polymer materials preparing with Biot number impacts. Shashikumar et al. [21] investigated the consistent progression of Williamson liquid in a miniature channel going with thick scattering, attractive field, and Joule dissemination. They detailed that liquid temperature declines when there are higher upsides of the Biot number. Rao et al. [22] talked about convectional nanofluid stream with gyrotactic microorganisms over an isothermal cone with Biot number impacts. Gangadhar et al. [23] investigated Biot number consequences for a nodal or saddle stagnation point stream of a fluid regular magnesium oxide-gold half-breed nanofluid with the slip system. Ahmad et al. [24] concentrated on the convective limit condition on the unstable progression of 2nd-grade nanofluid.

In the present scenario, researchers and designers are worried to experience the issues with regard to streams of liquids joined with synthetic responses. Substance responses could be homogeneous-heterogeneous. In the event that a response emerges inside the whole space, this response is named as homogeneous response, while the response reactants inside some particular district or inside the limit of the locale that could be heterogeneous response. Homogeneous-heterogeneous responses are likewise participating in various synthetically receptive frameworks. Here, note that a few responses develop on exceptionally low speed, and some of them do not advance by any means, without the presence of an impetus. An assortment of substance responses exist, and a large portion of them has critical utilizations in businesses and in compound architect frameworks. Especially, synthetic responses have generous effects in the creation of polymers, food regulation, pottery fabricating, hydrometallurgical industry, and artificial hardware plans and yield harm through freezing and forests of various trees. Numerous agents used heterogeneoushomogeneous responses in their examinations to research various sorts of stream marvels. At first, Chaudhary and Markin [25] introduced a straightforward model by utilizing heterogeneous-homogeneous responses in the progression of a gooey liquid almost at a stagnation point. Also, Merkin [26] mathematically investigated the limit layer stream by using heterogeneous-homogeneous responses. Khan et al. [27] introduced an altered warm conduction model by utilizing heterogeneous-homogeneous responses in the whirling stream of Maxwell liquid. They additionally examined that the nanoparticles' volume division appropriation debilitates for the homogeneous-heterogeneous responses' boundary. Mathematical recreation of Maxwell liquid stream because of the spiraling surface was done by Ahmed et al. [28]. They broke down that the focus rate lessens for bigger heterogeneous-homogeneous responses' boundary. The analysis for the flow of Williamson fluid with heterogeneous-homogeneous impacts bounded by the sheet and cylinder was examined by Hussain et al. [29]. Waqas [30] presented the heat transfer treatment for non-Newtonian ferromagnetic liquid subject to heterogeneous-homogeneous reactions. Rashid et al. [31] presented the mathematical analysis on the three-dimensional steady incompressible flow of Oldroyd-B fluid in the existence of heterogeneous-homogeneous impacts. $\mathrm{Xu}$ and $\mathrm{Xu}$ [32] inspected the heterogeneous-homogeneous response in the boundary layer flow of Buongiorno's model over a flat surface. Irfan et al. [33] implemented a theoretical study to investigate the response of homogeneous-heterogeneous in Oldroyd-B liquid with non-Fourier heat flux theory.

The indication of time-nondependent viscous fluid at rest over a hollow nonflatness cylinder was scrutinized by Wang [34]. The slippery flow due to the nonflatness cylinder was investigated by Wang and $\mathrm{Ng}$ [35]. Wang [34] introduced the behavior of the time-independent viscous fluid. By using the parameters of fluid and flow, the stretching cylinder was introduced, and this was studied by Crane [36]. Gangadhar et al. [37] scrutinized the flow of a couple of stress fluids over a stretched cylinder with nonuniform heat generation. Ahmed and Alhazmi [38] used FEM simulation to solve the rotation and radiation effects on cylinders within a lid-driven enclosure filled with glass balls. The problem of hydrodynamic and heat transfer of multidroplet impact on the cylindrical surfaces was analyzed by Luo et al. [39]. Kim 
and Kim [40] discussed an experimental investigation of natural convection flow features from vertical cylinders with diverged pin fins. Triveni and Panua [41] studied the mixed and natural convection flow of heated isothermal cylinders in a lid-driven square enclosure filled with nanofluid. Li et al. [42] investigated the activation energy and nonlinear thermal radiation in the unsteady flow of bioconvection in Maxwell nanofluid through a stretched cylinder. The stagnation point flow of a hybrid nanofluid above a stretching cylinder with a magnetic field was examined by Abbas et al. [43]. Song et al. [44] performed the unsteady boundary layer flow of Williamson nanofluid over a stretched cylinder. Recent studies have been made in [45-56].

In the applications of petrochemical, biochemical, engineering, and geophysical advances, the non-Newtonian fluid is most widely utilized based on the Burgers' fluid [57-61]. Homogeneous-heterogeneous reactions are impacted by employing the mass transfer rate features in the flow of Burgers' fluid by stretching the cylinder. Heat source impacts are dependent on the space and temperature parameters which are incorporated by using the convective heat flux model. Similarly, a feature of thermal properties is studied in a detailed manner. By using the PDEs, the phenomenon of mathematical modeling is performed. Transformations of similarity are converted into the ODEs. By using the distributions of flow, temperature, and solutal parameters, the RKF-45 method is developed, and this will explore the parameters based on the behavior of physical properties. In Section 2, the mathematical model is divided into two sections. RKF- 45 method I is utilized in Section 3 by solving the nonlinear differential equations. In Section 4, results are discussed. In Section 5, the discussion of conclusion remarks is studied finally.

\section{Mathematical Formulation}

The following four sections present a two-dimensional formulation using the axis of the present flow.

2.1. Flow Profile. A cylinder of radius $R$ is induced by stretching the model with two-dimensional flow. $z_{1}$-axis is obtained when the coordinates of the cylinder are settled along the cylinder. The radial direction is considered in the $r_{1}$-axis. $V=[u, 0, w]$ is considered as the present flow for the field of velocity. For the axis of $r_{1}$ and $z_{1}$, components of velocity are taken as $u$ and $w$. All this will be done by using the uniform magnetic field $B=\left[B_{0}, 0,0\right]$. This is applied to the flow of direction when applied in the normal condition. Stretching velocity of the cylinder in the $z_{1}$-axis is taken from $w_{s}=U_{0} z_{1} / l$. Reference velocity is represented as $U_{0}$, and specific length is represented as $l$ (Figure 1).

Khan et al. [17] showed and governed the present flow of equations for continuity and momentum:

$$
\begin{aligned}
& \frac{\partial u}{\partial r_{1}}+\frac{u}{r_{1}}+\frac{\partial w}{\partial z_{1}}=0 \\
& u \frac{\partial w}{\partial r_{1}}+w \frac{\partial w}{\partial z_{1}}+\lambda_{1}\left[u^{2} \frac{\partial^{2} w}{\partial r_{1}^{2}}+w^{2} \frac{\partial^{2} w}{\partial z_{1}^{2}}+2 u w \frac{\partial^{2} w}{\partial z_{1} \partial r_{1}}\right] \\
& +\lambda_{2}\left[\begin{array}{c}
u^{3} \frac{\partial^{3} w}{\partial r_{1}^{3}}+w^{3} \frac{\partial^{3} w}{\partial z_{1}^{3}}+2 u^{2}\left(\frac{\partial u}{\partial r_{1}} \frac{\partial^{2} w}{\partial r_{1}^{2}}+\frac{\partial w}{\partial r_{1}} \frac{\partial^{2} w}{\partial r_{1} \partial z_{1}}\right)-u^{2}\left(\frac{\partial w}{\partial z_{1}} \frac{\partial^{2} w}{\partial r_{1}^{2}}+\frac{\partial w}{\partial z_{1}} \frac{\partial^{2} w}{\partial r_{1}^{2}}\right)+w^{2}\left(\frac{\partial w}{\partial z_{1}} \frac{\partial^{2} w}{\partial z_{1}^{2}}-\frac{\partial w}{\partial r_{1}} \frac{\partial^{2} u}{\partial z_{1}^{2}}\right)+3 \mathrm{uw}\left(u \frac{\partial^{3} w}{\partial r_{1}^{2} \partial z_{1}}+w \frac{\partial^{3} w}{\partial z_{1}^{2} \partial r_{1}}\right) \\
+2 \mathrm{uw}\left(\left(\frac{\partial^{2} w}{\partial z_{1} \partial r_{1}}\right) \frac{\partial u}{\partial r_{1}}+\left(\frac{\partial u}{\partial z_{1}}\right) \frac{\partial^{2} w}{\partial r_{1}^{2}}+\left(\frac{\partial w}{\partial r_{1}}\right) \frac{\partial^{2} w}{\partial z_{1}^{2}}-\left(\frac{\partial^{2} u}{\partial r_{1} \partial z_{1}}\right) \frac{\partial w}{\partial r_{1}}\right)
\end{array}\right] \\
& =v \lambda_{3}\left[\begin{array}{c}
u \frac{\partial^{3} w}{\partial r_{1}^{3}}+w \frac{\partial^{3} w}{\partial r_{1}^{2} \partial z_{1}}+\frac{u}{r_{1}} \frac{\partial^{2} w}{\partial r_{1}^{2}}-\frac{\partial w}{\partial r_{1}} \frac{\partial^{2} u}{\partial r_{1}^{2}} \\
+\frac{w}{r_{1}}\left(\frac{\partial^{2} w}{\partial r_{1} \partial z_{1}}\right)-\frac{\partial w}{\partial r_{1}}\left(\frac{1}{r_{1}} \frac{\partial u}{\partial r_{1}}\right)-\frac{\partial w}{\partial z_{1}}\left(\frac{1}{r_{1}} \frac{\partial w}{\partial r_{1}}\right)-\left(\frac{\partial w}{\partial z_{1}}\right) \frac{\partial^{2} w}{\partial r_{1}^{2}}
\end{array}\right]+w_{e} \frac{\partial w_{e}}{\partial r_{1}}+v\left[\frac{\partial^{2} w}{\partial r_{1}^{2}}+\frac{1}{r_{1}} \frac{\partial w}{\partial r_{1}}\right] \\
& -\frac{\sigma B_{0}^{2}}{\rho}\left[\left(w-w_{e}\right)+\lambda_{1} u \frac{\partial w}{\partial r_{1}}+\lambda_{2}\left(w \frac{\partial u}{\partial z_{1}} \frac{\partial^{2} w}{\partial r_{1}^{2}}-u \frac{\partial w}{\partial z_{1}} \frac{\partial^{2} w}{\partial r_{1}^{2}}+\mathrm{uw} \frac{\partial^{2} w}{\partial r_{1} \partial z_{1}}+u^{2} \frac{\partial^{2} w}{\partial r_{1}^{2}}\right)\right],
\end{aligned}
$$

subject to the boundary conditions 


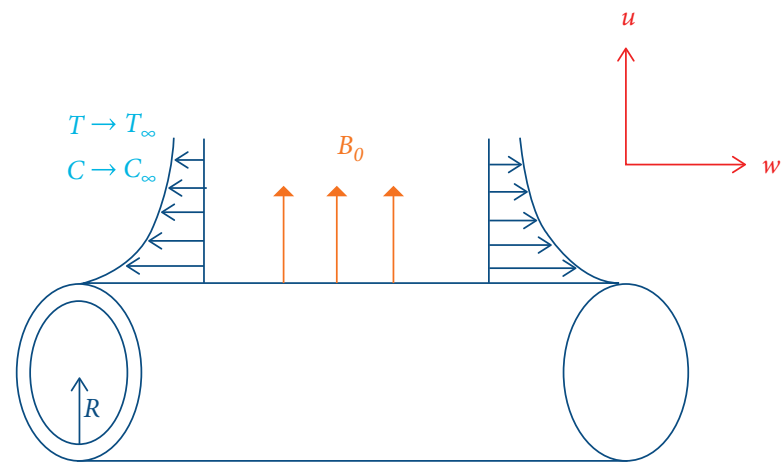

Figure 1: Physical sketch.

$$
\begin{aligned}
& w\left(r_{1}, z_{1}\right)=w_{s}=\frac{U_{0} z_{1}}{l}, \\
& u\left(r_{1}, z_{1}\right)=0 \text { at } r_{1}=R .
\end{aligned}
$$

$$
w\left(r_{1}, z_{1}\right) \longrightarrow w_{e}=\frac{U_{\infty} z_{1}}{l}, \frac{\partial w}{\partial r_{1}} \longrightarrow 0 \text { as } r \longrightarrow \infty .
$$

Here, $\lambda_{1}$ is the fluid relaxation time, $\lambda_{2}$ is the material factor of Burgers' fluid, $\lambda_{3}\left(\leq \lambda_{1}\right)$ is the fluid relaxation time, and $v$ is the kinematic viscosity of the fluid.

Transformations of similarity are shown in the following equation:

$$
\begin{aligned}
& u=-\frac{R}{r_{1}} \sqrt{\frac{U_{0} v}{l}} f_{1}(\eta), \\
& w=\frac{U_{0} z_{1}}{l} f_{1}^{\prime}(\eta), \\
& \eta=\sqrt{\frac{U_{0}}{v l}}\left(\frac{r_{1}^{2}-R^{2}}{2 R}\right) .
\end{aligned}
$$

(1) automatically satisfies when (5) is substituted into equations (1)-(4). The following form shows equations (2)-(4):

$$
\begin{aligned}
(1 & +2 \eta \alpha)^{2} \beta_{1}\left[2 f_{1}^{\prime \prime} f_{1} f_{1}^{\prime}-f_{1}^{\prime \prime} f_{1}^{2}\right]-(1+2 \eta \alpha) \beta_{1} \alpha f_{1}^{2} f_{1}^{\prime \prime} \\
& +(1+2 \eta \alpha)^{3} f_{1}^{\prime \prime}-4 \alpha^{2} \beta_{2} f_{1}^{\prime \prime} f_{1}^{\prime \prime}-4 \alpha \beta_{3}(1+2 \eta \alpha)^{2} f_{1}^{\prime \prime} f_{1} \\
& -(1+2 \eta \alpha)^{2} \beta_{2}\left[3 f_{1}^{\prime \prime} f_{1}^{2}+2 f_{1}^{\prime \prime} f_{1} f_{1}^{2}-f_{1}^{3} f_{1}^{\mathrm{iv}}\right] \\
& +(1+2 \eta \alpha) \alpha \beta_{2}\left[3 f_{1}^{\prime \prime} f_{1}^{2} f_{1}^{\prime}+f_{1}^{3} f_{1}^{\prime \prime}\right] \\
& +(1+2 \eta \alpha)^{2}\left[2 \alpha f_{1}^{\prime \prime}+f_{1} f_{1}^{\prime \prime}-f_{1}^{2}\right] \\
& +(1+2 \eta \alpha)^{3} \beta_{3}\left[f_{1}^{\prime \prime}-f_{1} f f_{1}^{\mathrm{iv}}\right] \\
& -(1+2 \eta \alpha)^{2} M^{2}\left[\beta_{2} f_{1}^{\prime \prime} f_{1}-\beta_{1} f_{1}^{\prime \prime} f_{1}+f_{1}^{\prime}-A\right] \\
& +(1+2 \eta \alpha)^{2} A^{2}=0, \\
f_{1}^{\prime} & =1, f_{1}=0 \text { at } \eta=0 \text { and } f_{1}^{\prime} \longrightarrow A, f_{1}^{\prime \prime} \longrightarrow 0 \text { as } \eta \longrightarrow 0 .
\end{aligned}
$$

Here, $\quad \alpha=1 / R \sqrt{v l / U_{0}}$ is the curvature factor, $\beta_{1}=\lambda_{1} U_{0} / l$ is the relaxation time parameter, $\beta_{2}=\lambda_{2}\left(U_{0} / l\right)^{2}$ is Burgers' fluid parameter, $\beta_{3}=\lambda_{3} U_{0} / l$ is the fluid relaxation time parameter, the magnetic force parameter is represented as $M=\left(\sigma \mathrm{BB}_{0}^{2} / \rho_{f} U_{0}\right)^{1 / 2}$, and the velocity ratio parameter is represented as $A=w_{e} / w_{s}$.

2.2. Thermal Features of Burgers' Fluid. In the present case, the heat transport equation is given as shown in the following:

$$
\left(\rho c_{p}\right)\left(u \frac{\partial T}{\partial r_{1}}+w \frac{\partial T}{\partial z_{1}}\right)=k\left(\frac{\partial^{2} T}{\partial r_{1}^{2}}+\frac{1}{r_{1}} \frac{\partial T}{\partial r_{1}}\right)+q^{\prime \prime \prime} .
$$

The following shows the boundary conditions which are related with each other:

$$
-k \frac{\partial T}{\partial r_{1}}=h_{f}\left(T_{f}-T\right) \text { at, } \quad r_{1}=R \text { and } T \longrightarrow T_{\infty} \text { as } r_{1} \longrightarrow \infty,
$$

where $k$ is the thermal conductivity, $\rho$ is the density, $T$ is the temperature, $T_{f}$ is the convective surface temperature with heat transfer coefficient $h_{f}$, and $c_{p}$ is the specific heat at constant pressure.

$q^{\prime \prime \prime}$ is the space- and temperature-related internal heat generation/absorption which can be conveyed in the simplest form as (Song et al. [44])

$$
q^{\prime \prime \prime}=\frac{\mathrm{kw}_{s}}{z_{1} v}\left[A^{*}\left(T_{f}-T_{\infty}\right) f_{1}^{\prime}+B^{*}\left(T-T_{\infty}\right)\right] .
$$

Here, space and temperature parameters depend on the internal heat generation/absorption, and these are represented as $A^{*}$ and $B^{*} . A^{*}>0$ and $B^{*}>0$ show that values are corresponded to the internal heat generation, and $A^{*}>0$ and $B^{*}>0$ show that values are corresponded to the internal heat absorption.

The following shows Burgers' fluid which is based on the dimensionless temperature:

$$
\theta(\eta)=\frac{T-T_{\infty}}{T_{f}-T_{\infty}}
$$

By making use of equations (10) and (11) into equations (8) and (9), we get 


$$
\begin{aligned}
& (1+2 \alpha \eta) \theta^{\prime \prime}+2 \alpha \theta^{\prime}+\operatorname{Pr} f_{1} \theta^{\prime}+A^{*} f_{1}^{\prime}+B^{*} \theta=0, \\
& \theta^{\prime}=-\operatorname{Bi}(1-\theta) \text { at, } \quad \eta=0 \theta \longrightarrow 0 \text { as } \eta \longrightarrow \infty .
\end{aligned}
$$

Here, the Prandtl number is represented as $\operatorname{Pr}=\mu c_{p} / k$, and the Biot number is represented as Bilh $f / k$.

2.3. Relation for Chemical Species. Hence, chemical reactants have $\left(a_{1}, a_{2}\right)$ as concentrations with $\left(k_{c}, k_{s}\right)$ as rate constants by assuming the $(G, H)$ values. Cubic autocatalysis is assumed by maintaining the response of homogeneous, and it is shown from the following equation:

$$
A+2 B \longrightarrow 3 B, \text { rate }=k_{c} a_{1} a_{2}^{2} .
$$

The following shows the representation of isothermal response which is at the first order by maintaining the surface of the catalyst as heterogeneous:

$$
A \longrightarrow B \text {, rate }=k_{s} a_{1} \text {. }
$$

Isothermal reactants are utilized, and it is assumed that the ambient fluid is taken far away from the surface; uniform concentration of reactant $A$ is represented using $a_{0}$ when the autocatalyst is not existed. Hence, the species will govern the equations based on the limitations which are given in the following:

$$
\begin{aligned}
& u \frac{\partial a_{1}}{\partial r_{1}}+w \frac{\partial a_{2}}{\partial z_{1}}=D_{G}\left(\frac{1}{r_{1}} \frac{\partial a_{1}}{\partial r_{1}}+\frac{\partial^{2} a_{1}}{\partial r_{1}^{2}}\right)-k_{c} a_{1} a_{2}^{2}, \\
& u \frac{\partial a_{2}}{\partial r_{1}}+w \frac{\partial a_{2}}{\partial z_{1}}=D_{H}\left(\frac{1}{r_{1}} \frac{\partial a_{2}}{\partial r_{1}}+\frac{\partial^{2} a_{2}}{\partial r_{1}^{2}}\right)+k_{c} a_{1} a_{2}^{2},
\end{aligned}
$$

with associated boundary conditions as

$$
\begin{gathered}
D_{G} \frac{1}{r_{1}} \frac{\partial a_{1}}{\partial r_{1}}=k_{s} a_{1}, \\
D_{H} \frac{1}{r_{1}} \frac{\partial a_{2}}{\partial r_{1}}=-k_{s} a_{1}, \text { at } r_{1}=R . \\
a_{1} \longrightarrow a_{0}, a_{2} \longrightarrow 0 \text { as } r_{1} \longrightarrow \infty .
\end{gathered}
$$

Here, the coefficient of diffusion for the species $G$ is represented using $D_{G}$, whereas diffusion coefficient for species $H$ is represented using $D_{H}$.

The following shows the transformations which are in use:

$$
\begin{aligned}
& a_{1}=a_{0} \phi(\eta), \\
& a_{2}=b_{0} \psi(\eta) .
\end{aligned}
$$

Equations (14)-(18) show the transformations:

$$
\begin{aligned}
& B\left((1+2 \alpha \eta) \phi^{\prime \prime}+2 \alpha \phi^{\prime}\right) \frac{1}{\mathrm{Sc}}+f_{1} \phi^{\prime}-k_{1} \phi \psi^{2}=0, \\
& \left((1+2 \alpha \eta) \psi^{\prime \prime}+2 \alpha \psi^{\prime}\right) \frac{\lambda^{*}}{\mathrm{Sc}}+f_{1} \psi^{\prime}+k_{1} \phi \psi^{2}=0, \\
& \phi^{\prime}(0)=k_{2} \phi(0), \\
& \lambda^{*} \psi^{\prime}(0)=-k_{2} \phi(0), \\
& \phi \longrightarrow 1, \psi \longrightarrow 0, \quad \text { as } \eta \longrightarrow \infty .
\end{aligned}
$$

Here, diffusion coefficient is represented as $\lambda^{*}=D_{H} / D_{G}$, homogeneous reaction constant is represented as $k_{1}$, heterogeneous reaction constant is represented as $k_{2}$, and Schmidt number is represented as $\mathrm{Sc}=v / D_{a}$.

When $D_{H}=D_{G}$, coefficients of diffusion quality are assumed based on the quality. $\lambda^{*}=1$ shows the implication of this quality. $\phi(\eta)+\psi(\eta)=1$ shows the coefficients of diffusion quality.

Hence, the following shows the proof:

$$
\begin{aligned}
& \left((1+2 \alpha \eta) \phi^{\prime \prime}+2 \alpha \phi^{\prime}\right) \frac{1}{\mathrm{Sc}}+f_{1} \phi^{\prime}-k_{1} \phi(1-\phi)^{2}=0 . \\
& \phi^{\prime}(0)=k_{2} \phi(0) \text { and } \phi \longrightarrow 1 \text { as } \eta \longrightarrow \infty
\end{aligned}
$$

2.4. Heat Transfer Performance. Local Nusselt number $\mathrm{Nu}_{z}$ is estimated by the performance of convective heat transfer over the cylindrical surface. The Nusselt number is utilized using $\mathrm{Nu}_{\mathrm{z}}$. The following shows the quality of mathematical expression:

$$
\mathrm{Nu}_{z}=\frac{z_{1} q_{w}}{k\left(T_{f}-T_{\infty}\right)}
$$

with $q_{w}=-k\left(\partial T / \partial r_{1}\right)_{r_{1}=R}$

The following equation shows the nondimensional form:

$$
\operatorname{Re}^{1 / 2} \mathrm{Nu}_{z}=-\theta^{\prime}(0),
$$

where $\operatorname{Re}=z_{1} w_{s} / v$ is the local Reynolds number.

\section{Method of the Solution}

The nonlinear equations (6), (12), and (23) under conditions (7), (13), and (23) are solved via the shooting technique along with the Runge-Kutta-Fehlberg fourth and fifth order method. Computation is performed with the aid of MATLAB. Equations (6), (12), and (23) are written as 


$$
f_{1}^{\text {iv }}=\frac{1}{\left[\begin{array}{c}
(1+2 \alpha \eta)^{3} f_{1} \beta_{3} \\
-(1+2 \alpha \eta)^{2} \beta_{2} f_{1}^{3}
\end{array}\right]}\left[\begin{array}{c}
(1+2 \alpha \eta)^{2} \beta_{1}\left[2 f_{1} f_{1}^{\prime} f_{1}^{\prime \prime}-f^{2} f_{1}^{\prime \prime}\right] \\
-(1+2 \alpha \eta) \alpha \beta_{1} f_{1}^{2} f_{1}^{\prime \prime}+(1+2 \alpha \eta)^{3} f_{1}^{\prime \prime} \\
-4 \alpha^{2} \beta_{2} f_{1}^{\prime \prime} f_{1}^{\prime \prime}-4 \alpha \beta_{3}(1+2 \alpha \eta)^{2} f_{1} f_{1}^{\prime \prime} \\
-(1+2 \alpha \eta)^{2} \beta_{2}\left[3 f_{1}^{2} f_{1}^{\prime \prime 2}+2 f_{1} f_{1}^{2} f_{1}^{\prime \prime}\right] \\
+(1+2 \alpha \eta) \alpha \beta_{2}\left[3 f_{1}^{2} f_{1}^{\prime} f_{1}^{\prime \prime}+f_{1}^{3} f_{1}^{\prime \prime}\right] \\
\theta^{\prime \prime}=-\frac{1}{(1+2 \alpha \eta)}\left[2 \alpha \theta^{\prime}+\operatorname{Pr} f_{1} \theta^{\prime}+A^{*} f_{1}^{\prime}+B^{*} \theta\right], \\
+\left(1+2 \alpha \eta f_{1}^{3} \beta_{3}\left[f_{1}^{\prime \prime} f_{1}^{\prime \prime}-f_{1}^{\prime}\right]\right. \\
-(1+2 \alpha \eta)^{2} M^{2}\left[\begin{array}{c}
\beta_{2} f_{1} f_{1}^{\prime \prime}-\beta_{1} f_{1} f_{1}^{\prime \prime} \\
+f_{1}^{\prime}-A
\end{array}\right], \\
\phi^{\prime \prime}=-\frac{1}{(1+2 \alpha \eta)}\left[2 \alpha \phi^{\prime}+\operatorname{Scf} \phi_{1} \phi^{\prime}-\operatorname{Sck}_{1} \phi(1-\phi)^{2}\right] .
\end{array}\right]
$$

The first-order corresponding scheme in terms of variables
$\left(\Psi_{1}, \Psi_{2}, \Psi_{3}, \Psi_{4}, \Psi_{5}, \Psi_{6}, \Psi_{7}, \Psi_{8}\right)=\left(f_{1}, f_{1}^{\prime}, f_{1}^{\prime \prime}, f_{1}^{\prime \prime}, \theta, \theta^{\prime}, \phi\right.$, $\left.\phi^{\prime}\right)$ is

$$
\begin{aligned}
& \Psi_{1}^{\prime}=\Psi_{2}, \\
& \Psi_{2}^{\prime}=\Psi_{3}, \\
& \Psi_{3}^{\prime}=\Psi_{4},
\end{aligned}
$$

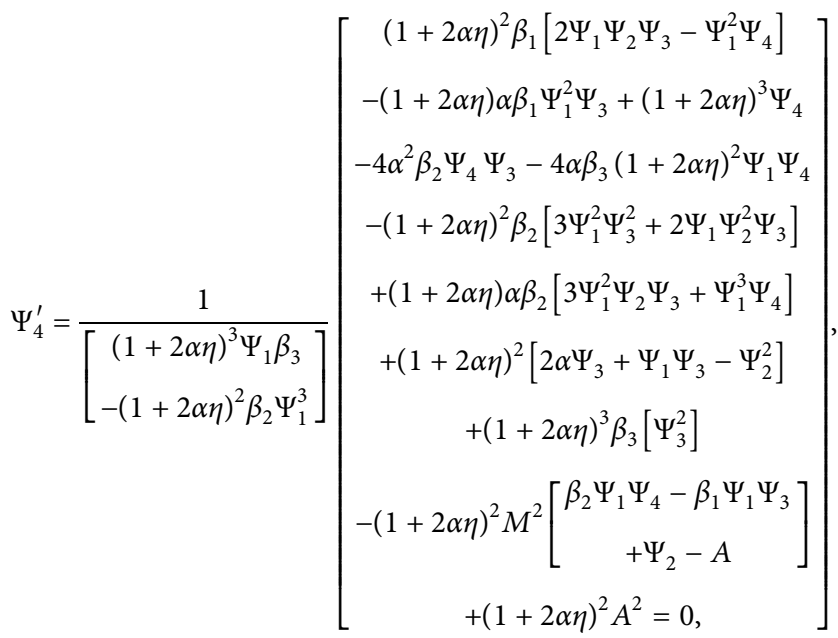

$\Psi_{5}^{\prime}=\Psi_{6}$,

$\Psi_{6}^{\prime}=-\frac{1}{(1+2 \alpha \eta)}\left[2 \alpha \Psi_{6}+\operatorname{Pr} \Psi_{1} \Psi_{6}+A^{*} \Psi_{2}+B^{*} \Psi_{5}\right]$,

$\Psi_{7}^{\prime}=\Psi_{8}$,

$\Psi_{5}^{\prime}=-\frac{1}{(1+2 \alpha \eta)}\left[2 \alpha \Psi_{8}+\mathrm{Sc} \Psi_{1} \Psi_{8}-\mathrm{Sc} k_{1} \Psi_{7}\left(1-\Psi_{7}\right)^{2}\right]$, 
with

$$
\begin{aligned}
\Psi_{1}(0) & =0, \\
\Psi_{2}(0) & =1, \\
\Psi_{3}(0) & =s_{1}, \\
\Psi_{6}(0)+B i\left(1-\Psi_{5}(0)\right) & =0, \\
\Psi_{6}(0) & =s_{2}, \\
\Psi_{7}(0) & =1, \\
\Psi_{8}(0) & =s_{3}, \\
\Psi_{2}(\infty) & =A, \\
\Psi_{3}(\infty) & =0, \\
\Psi_{5}(\infty) & =0, \\
\Psi_{7}(\infty) & =0 .
\end{aligned}
$$

RKF-45 method will solve the unknown initial conditions $\left(s_{1}, s_{2}, s_{3}\right)$ based on the IVP which is an appropriate choice. Benchmarks $\left(\max \left\{\Psi_{1}, \Psi_{2}, \Psi_{5}, \Psi_{7}\right\}<\varepsilon\right)$ are improved by assuring Newton's method. Any positive number is signified based on $(\varepsilon>0) . \varepsilon=10^{-6}$ will be obtained from the analysis of numerical results.

3.1. Validation of Results. Irfan et al. [33], Waqas et al. [11], and Subhas Abel et al. [10] validated the results by comparing the parameters after execution. Extra parameters are nullified by comparing the present results of skin friction coefficient against the pertinent parameter $\beta$, and this is shown in Table 1 with $[10,11,33]$. From Table 2 , it can be observed that Shehzad et al. [18], Hayat et al. [16], and Khan et al. [17] compared the skin friction coefficient against the significant parameter $M$. Present results are validated by observing the comparisons of appropriate resemblance.

\section{Results and Discussion}

By using the mathematical formulation section, the ODEs are characterized and planned based on the physical constraints. The investigation of physical behavior is done for various parameters in the RKF-45 method. From equations (6), (13), and (23), the ODEs are depicted and mentioned in equations (7), (14), and (25). From Figures 2-8, the distributions of solutal, temperature, and flow are impacted and depicted. For numerical simulation, the leading parameters are allocated for fixed values; they are $\alpha=0.1, \beta_{1}=0.7, \beta_{2}=$ $0.25, \beta_{3}=0.5, M=2, \operatorname{Pr}=6.2, k_{1}=0.4, A=0.2, k_{2}=0.5, B i$ $=0.5, A^{*}=0.01, B^{*}=0.1$, and $\mathrm{Sc}=6.0$, and from graphs, few are mentioned. Behaviors of involved parameters are introduced by physical interpretation and deliberation. Figure 2 shows the hydromagnetic flow situation and hydrodynamic flow patterns. Stagnation $z_{1}=0$ of the hydrodynamic flow situation in hydromagnetic flow streamlines is closed.
From Figures 3(a)-3(c), the distributions of velocity, temperature, and solutal are provided against the magnetic force parameter $(M)$ and curvature parameter $(\alpha)$ which are an impact of combined characteristics. Large curvature parameter will become high when the flow of concentration curves of the fluid enhances and accesses the curves. In limiting sense, the radius of cylinder shrinks with curvature. The fluid will be build up when the resistance is produced with exterior diminution. The values of the curvature parameter are intensified using the thermal curves of Burgers' fluid in the upsurge. From these figures, it can be observed that the thermal boundary conditions are analyzed and satisfied due to the flow of patterns. The magnetic force parameter $(M)$ is affected by using Burgers' fluid, and this will escalate the data using parameters.

A drag force is generated based on the effect of the magnetic force parameter. This force consists of intensifying nature which will oppose the motion of liquid flow, and the liquid deteriorates of velocity. A higher extent of the magnetic parameter is declined using the thermal energy transport perception which is a basic flow. Stronger Lorentz force is utilized based on the large magnetic parameter. Thermal profile of Burgers' fluid is developed by using the force parameters ultimately. Hence, larger values are assigned to the magnetic force parameter which is declined by the concentration rate. Hydromagnetic flow situation is corresponded to $M \neq 0$ when it is classified by the hydrodynamic flow pattern. 0.0 to 1.5 is the range that is analyzed by $M$.

From Figures $4(\mathrm{a})-4(\mathrm{c})$, the material parameter for Burgers' fluid $\left(\beta_{2}\right)$ against flow, temperature, concentration curves, and fluid relaxation time $\left(\beta_{1}\right)$ impact are shown in a detailed manner. Momentum boundary layer of Burgers' fluid is diminished based on the thickness. Large values of $\beta_{1}$ are scrutinized which will lead to the profile. Fluid relaxation time parameter is utilized by Burgers' fluid buildup technique which will escalate the data in a very effective way. Based on the relaxation time $\lambda_{1}$, the value of $\beta_{1}$ is dependent. Various effects are opposed by escalating the Deborah number $\beta_{1}$ and fluid motion which is augmented based on the fluid relaxation time. In this, victim diminution will depend on Burgers' fluid flow curves which are mainly improving the strength. Deborah number $\left(\beta_{1}\right)$ is escalated by intensifying the fluid elements' improvement, and this will mainly increase the interface flows. Burgers' fluid will improve the flow by raising the thermal energy transport. Deborah number $\beta_{1}$ large values are obtained by associating the thickness of the boundary layer and concentration curves. 0.5 to 3.5 range is obtained for the $\beta_{1}$ values after analyzing. Magnitude of $\beta_{2}$ is enlarged by enlarging the thickness of the velocity boundary layer, and this is shown from Figures 4(a)-4(c) which will attenuate the flow of curves. Scales are varied based on Burgers' fluid parameter by augmenting the thermal profile. Higher magnitude of $\beta_{2}$ is obtained by decreasing 
TABLE 1: For various values of $\beta_{1}, \alpha=\beta_{2}=\beta_{3}=M=0$ against $-f^{\prime \prime}(0)$ comparison table.

\begin{tabular}{lcccc}
\hline$\beta_{1}$ & Subhas Abel et al. [10] & Irfan et al. [33] & Waqas et al. [11] & Present results \\
\hline 0.0 & 1.000000 & 1.0000000 & 1.000000 & 1.00000000 \\
0.2 & 1.051948 & 1.0518890 & 1.051889 & 1.101903 \\
0.4 & 1.101850 & 1.1019035 & 1.150137 & 1.10190328 \\
0.6 & 1.150163 & 1.1501374 & 1.196711 & 1.15013735 \\
0.8 & 1.196692 & 1.1967114 & - & 1.19671127 \\
1.0 & - & 1.2417477 & 1.285363 & 1.24174749 \\
1.2 & 1.285257 & 1.2853630 & - & 1.28536328 \\
1.4 & - & 1.3276675 & 1.368758 & 1.32766723 \\
1.6 & 1.368641 & 1.3687582 & - & 1.36875824 \\
1.8 & - & 1.4087264 & 1.447651 & 1.40872641 \\
2.0 & 1.447617 & 1.4476526 & 1.44765068 \\
\hline
\end{tabular}

TABLe 2: Comparative study of the present results for $-f^{\prime \prime}(0)$ against $\alpha=\beta_{1}=\beta_{2}=\beta_{3}=0$.

\begin{tabular}{lcccc}
\hline$M$ & Shehzad et al. [18] & Hayat et al. [16] & Khan et al. [17] & Present results \\
\hline 0.0 & 1.00000 & 1.00000 & 1.000000 & 1.00000000 \\
0.2 & 1.01980 & 1.01980 & 1.019801 & 1.01980390 \\
0.5 & 1.11803 & 1.11803 & 1.118029 & 1.11803399 \\
0.8 & 1.28063 & 1.28063 & 1.280633 & 1.28062485 \\
1.0 & 1.41421 & 1.41421 & 1.414221 & 1.562048 \\
1.2 & 1.56205 & 1.56205 & 1.803044 & 1.56204994 \\
1.5 & 1.80303 & 1.80303 & & 1.80277564 \\
\hline
\end{tabular}

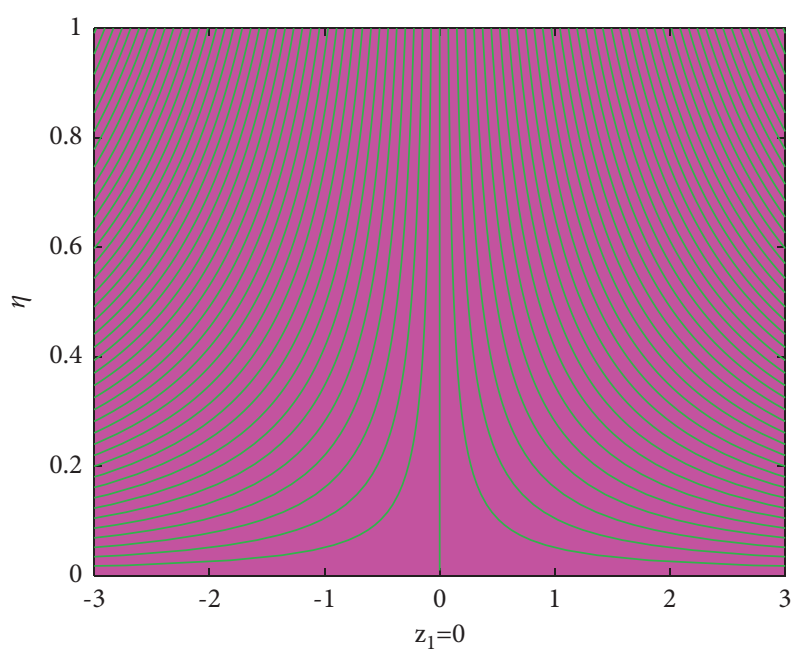

(a)

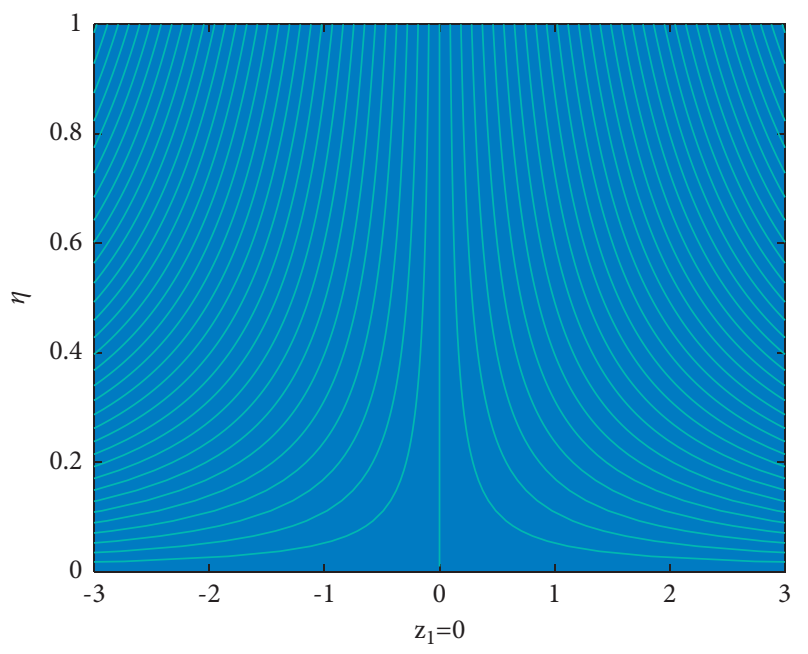

(b)

Figure 2: (a) $M=0$ streamlines. (b) $M=2$ streamlines.

the thickness of boundary layers which depend on the concentration curves. 2.5 to 5.5 range is taken for the value of $\beta_{2}$ by scrutinizing.

From Figures 5(a)-5(c), the solutal, temperature, and retardation time parameter $\left(\beta_{3}\right)$ against flow distributions are characterized. By concentrating the profiles of
Burgers' fluid rise, the flow is detected. Deborah number $\beta_{3}$ will diminish the values of thermal energy transport. Retardation time $\lambda_{3}$ is enlarged physically. Non-Newtonian viscoelastic fluid model will use the two situations to reduce the viscous fluid model by detecting it. They are given as (1) $\lambda_{1}=\lambda_{2}=\lambda_{3},(2) \lambda_{2}=0$, and (3) $\lambda_{1}=\lambda_{3}$. Fluid 


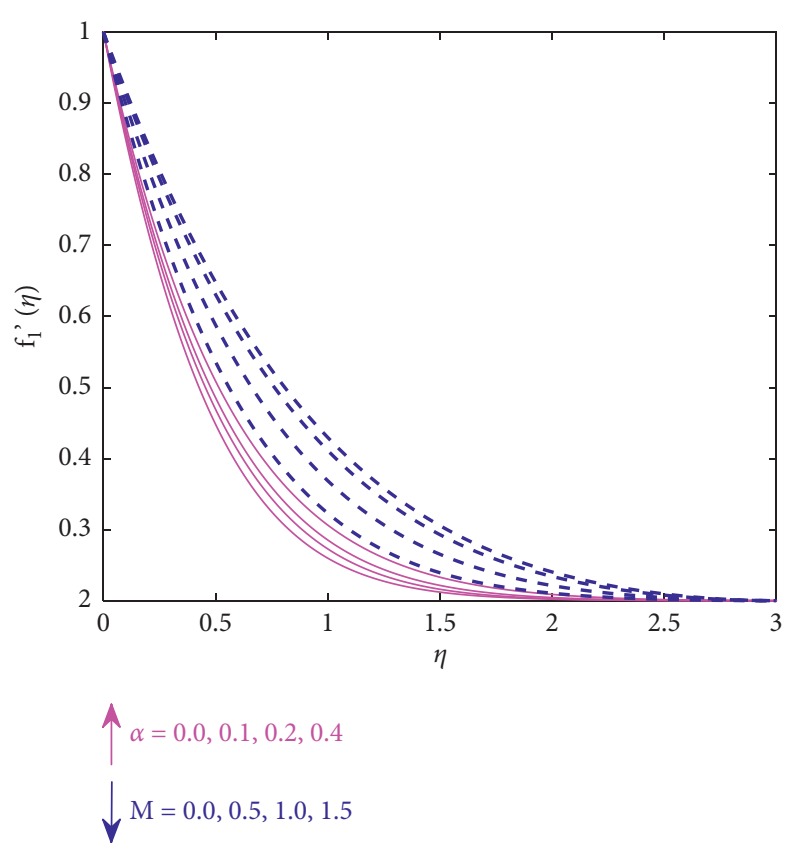

(a)
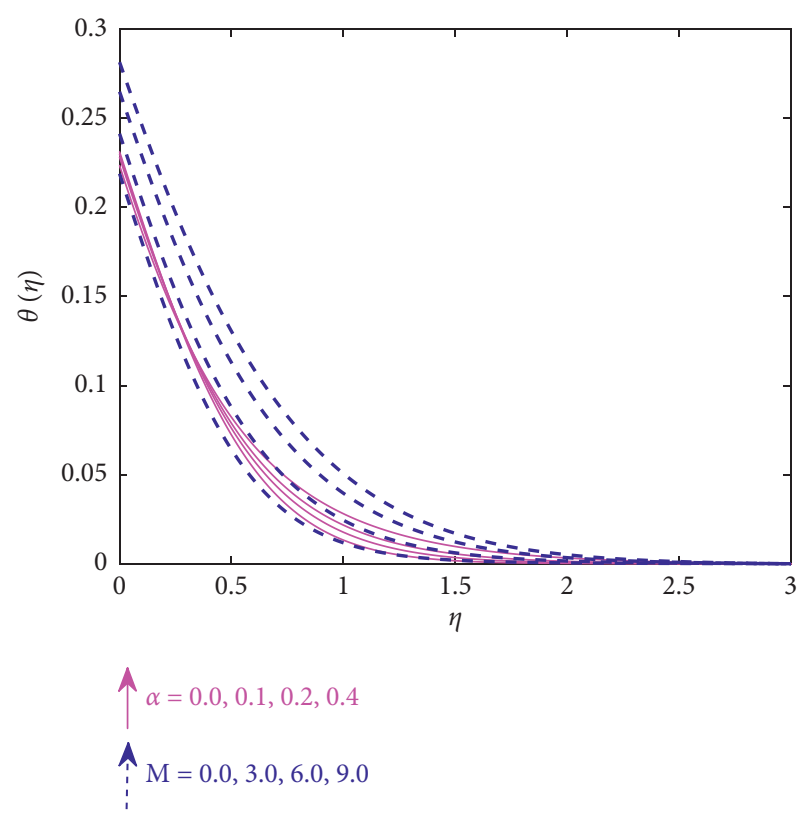

(b)

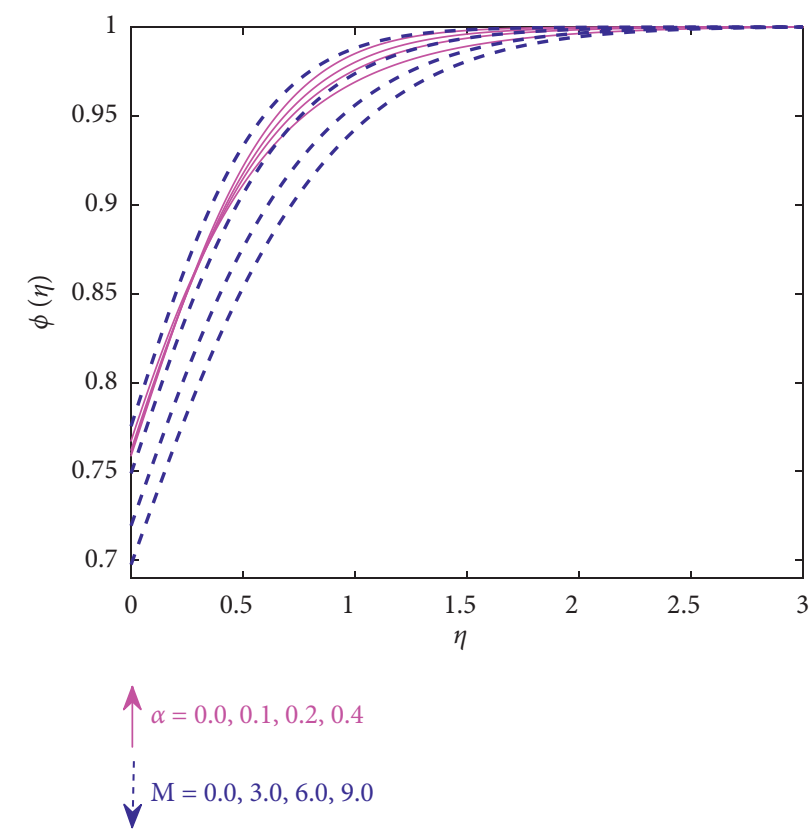

(c)

Figure 3: (a) Variation of $f_{1}^{\prime}(\eta)$ versus $\alpha$ and $M$. (b) Variation of $\theta(\eta)$ versus $\alpha$ and $M$. (c) Variation of $\phi(\eta)$ versus $\alpha$ and $M$.

retardation time will become equal when the parameters of Burgers' fluid are utilized, and this is the first case in fluid relaxation time.

Vanished Burgers' fluid parameter is elaborated by maintaining the retardation time. Maxwell viscoelastic fluid model will describe this position based on the $\lambda_{2}=\lambda_{3}=0$ description. Relaxation time $\beta_{1}$ will control the distribution by maintaining the value of fluid relaxation time $\beta_{3}$.

By using the hydrodynamic and hydromagnetic flow situations, Burgers' liquid flow distributions will utilize the velocity ratio parameter $(A)$, and this is shown from Figure 6(a). The phenomenon of flow is detected from this 

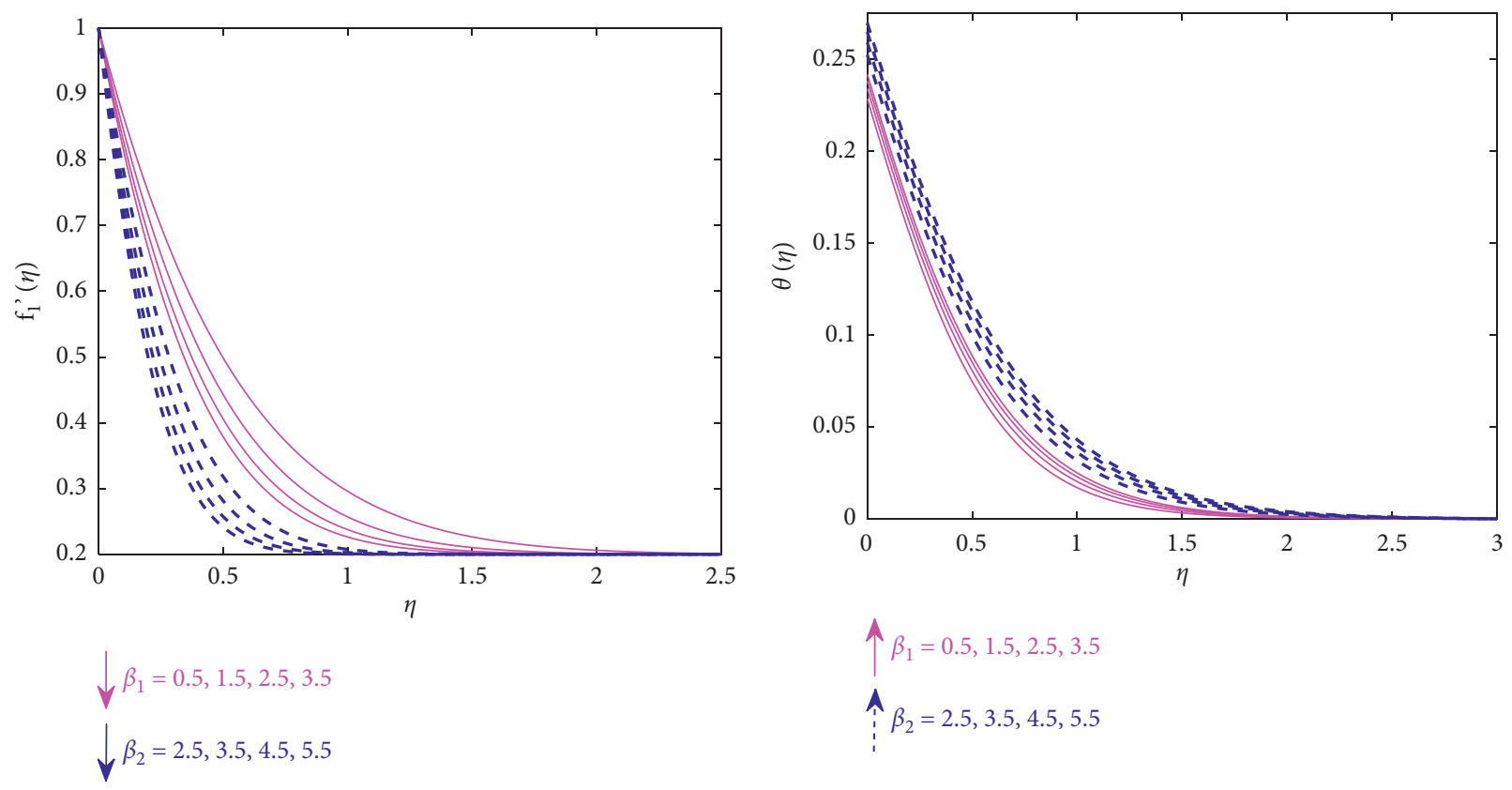

(a)

(b)

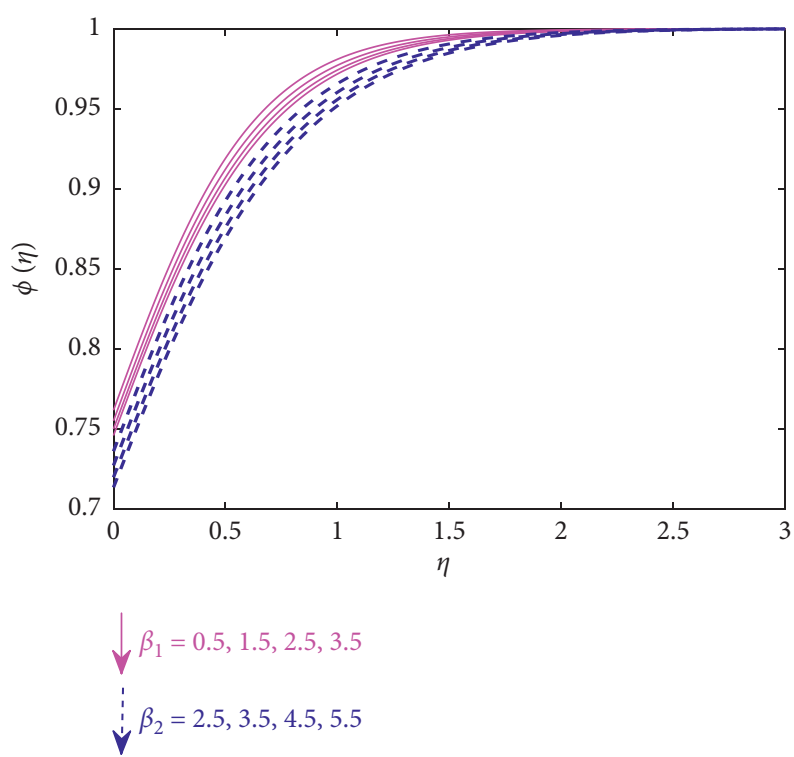

(c)

Figure 4: (a) Variation of $f_{1}^{\prime}(\eta)$ versus $\beta_{1}$ and $\beta_{2}$. (b) Variation of $\theta(\eta)$ versus $\beta_{1}$ and $\beta_{2}$. (c) Variation of $\phi(\eta)$ versus $\beta_{1}$ and $\beta_{2}$.

plot. In Burgers' liquid, boundary layer thickness will improve the magnitude velocity of ratio constant $(A<1)$.

Figure 6(b) is to feature the actual impact of the temperature profile inside the heat source $\left(A^{*}\right.$ and $\left.B^{*}\right)$ against temperature of Burgers' liquid. From this diagram, it is related that the temperature of the liquid is essentially influenced by the boundaries $\left(A^{*}\right.$ and $\left.B^{*}\right)$. An unmistakable upsurge is distinguished in the temperature profile of Burgers' liquid because of acceleration in the improvement of the heat source $\left(A^{*}\right.$ and $\left.B^{*}\right)$. By taking assumptions in the framework expansion will improve the heating rise eventually. This heat rising condition of the fluid is highlighted by bringing the assumptions of heightening. These outcomes are like those of Song et al. [44].
From Figure 6(c), it is shown that Prandtl number (Pr) and Biot number $(B i)$ are against the Burgers' fluid temperature features. Prandtl number is varied by extending magneto-Burgers' liquid which is inspected from the thermal counters. Based on the thermal diffusivity function, the Prandtl number $\operatorname{Pr}$ is utilized. Temperature distribution coefficient is analyzed by accessing the Prandtl number in a higher form. Thermal profiles decline for higher Pr and thickness of temperature from the boundary using Burgers' liquid. 3.0 to 6.0 is the range of the Prandtl number for realization.

From Figure 7, it shows that the heterogeneous and homogeneous response parameters $\left(k_{1}\right.$ and $\left.k_{2}\right)$ are impacted 


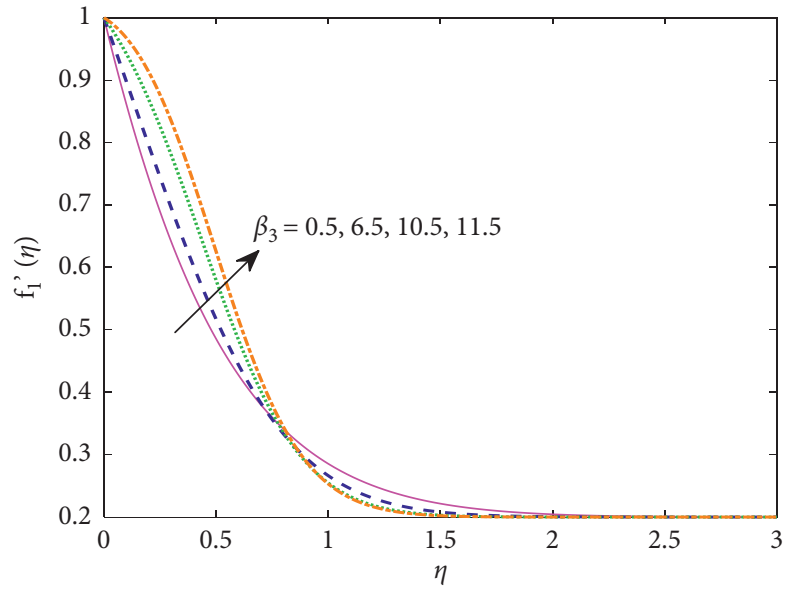

(a)

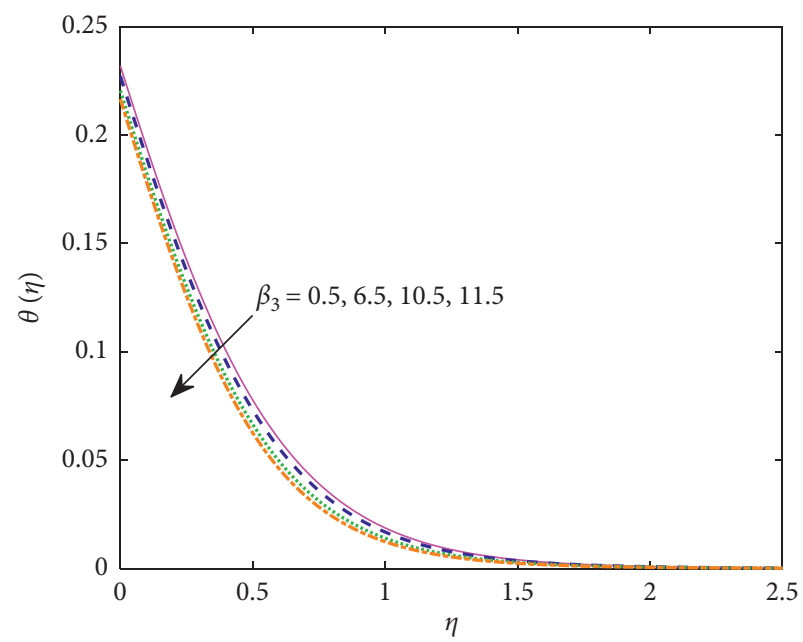

(b)

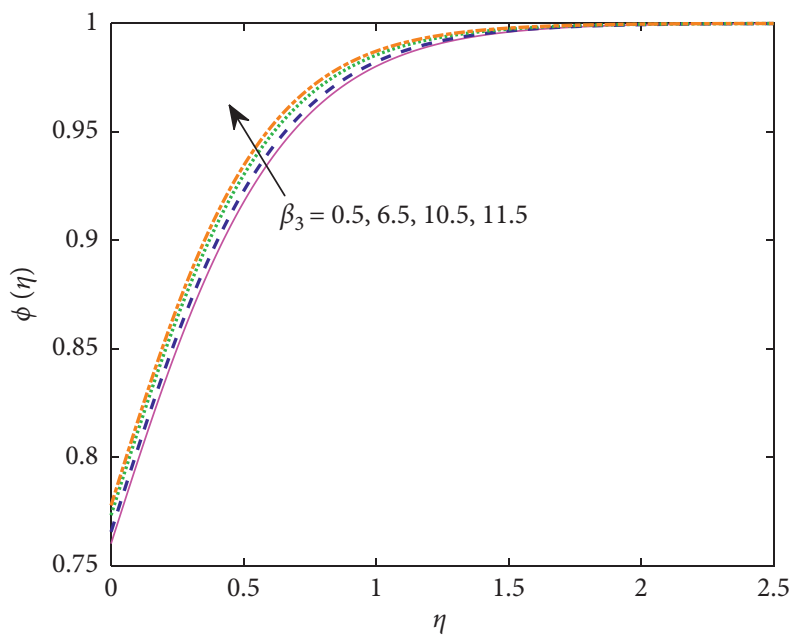

(c)

Figure 5: (a) Variation of $f_{1}^{\prime}(\eta)$ versus $\beta_{3}$. (b) Variation of $\theta(\eta)$ versus $\beta_{3}$. (c) Variation of $\phi(\eta)$ versus $\beta_{3}$.
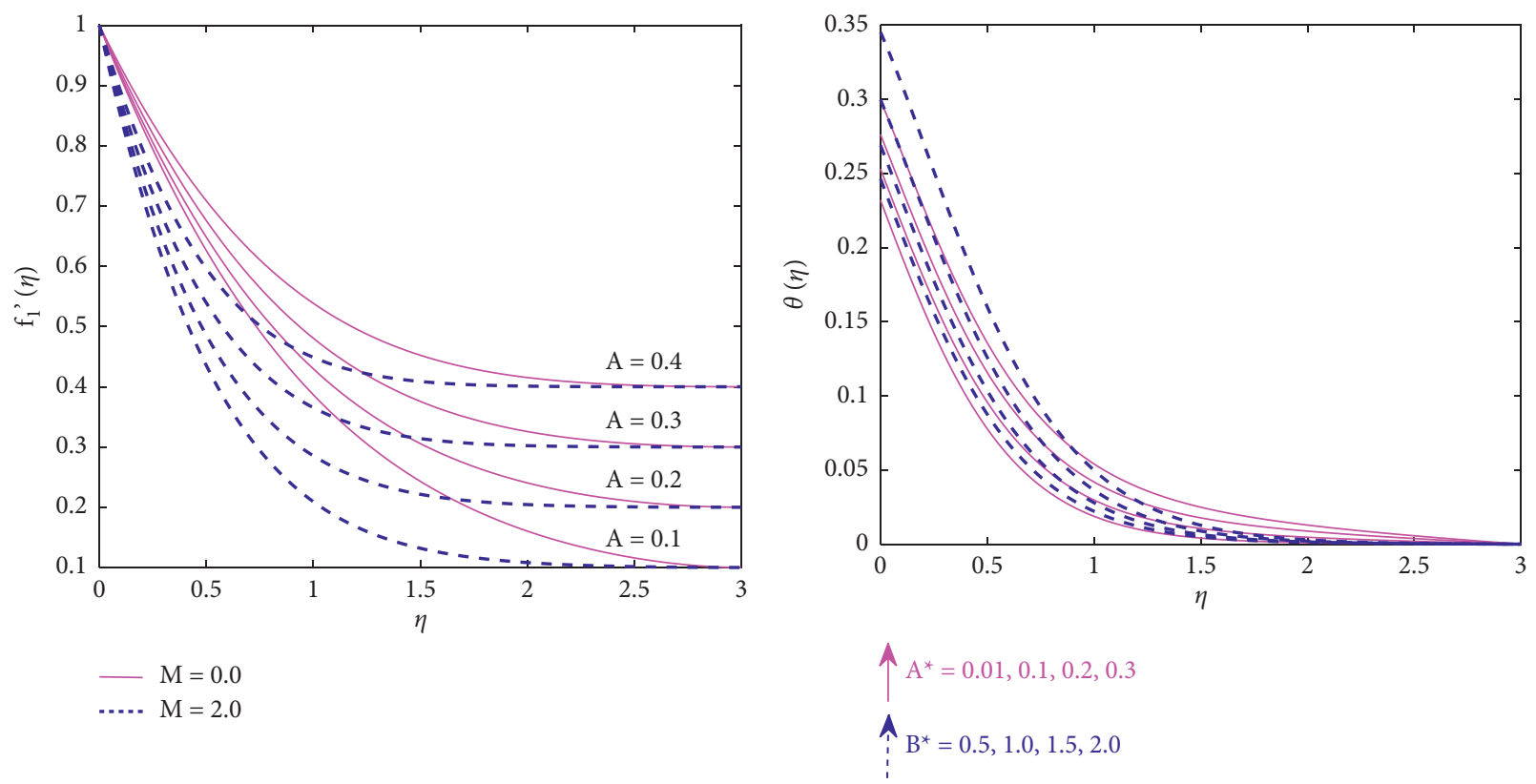

(a)

Figure 6: Continued. 


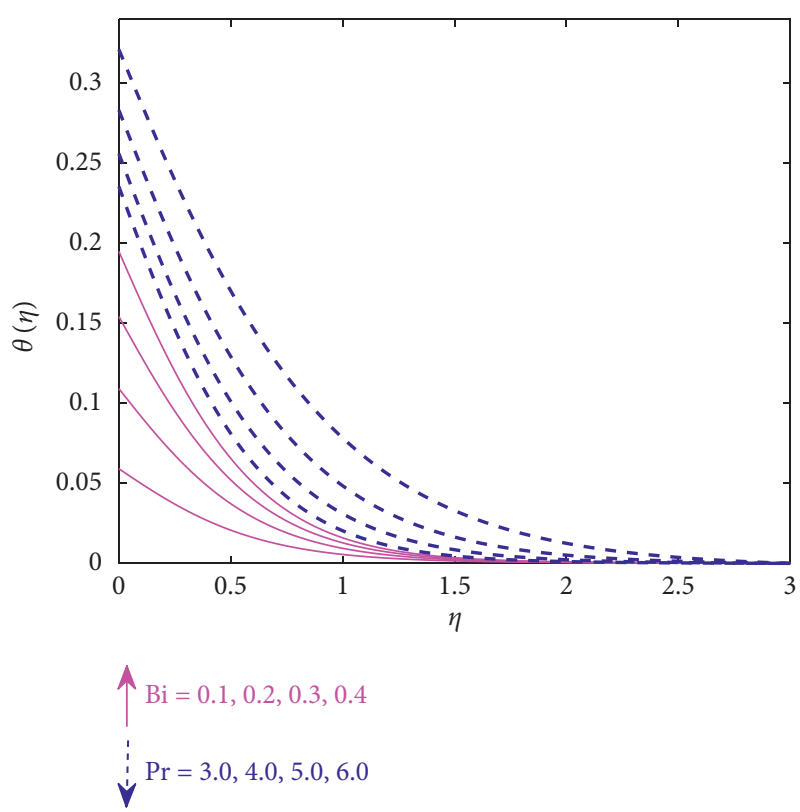

(c)

Figure 6: (a) Variation of $f_{1}^{\prime}(\eta)$ versus $A$ and $M$. (b) Variation of $\theta(\eta)$ versus $A^{*}$ and $B^{*}$. (c) Variation of $\phi(\eta)$ versus $B i$ and $P r$.

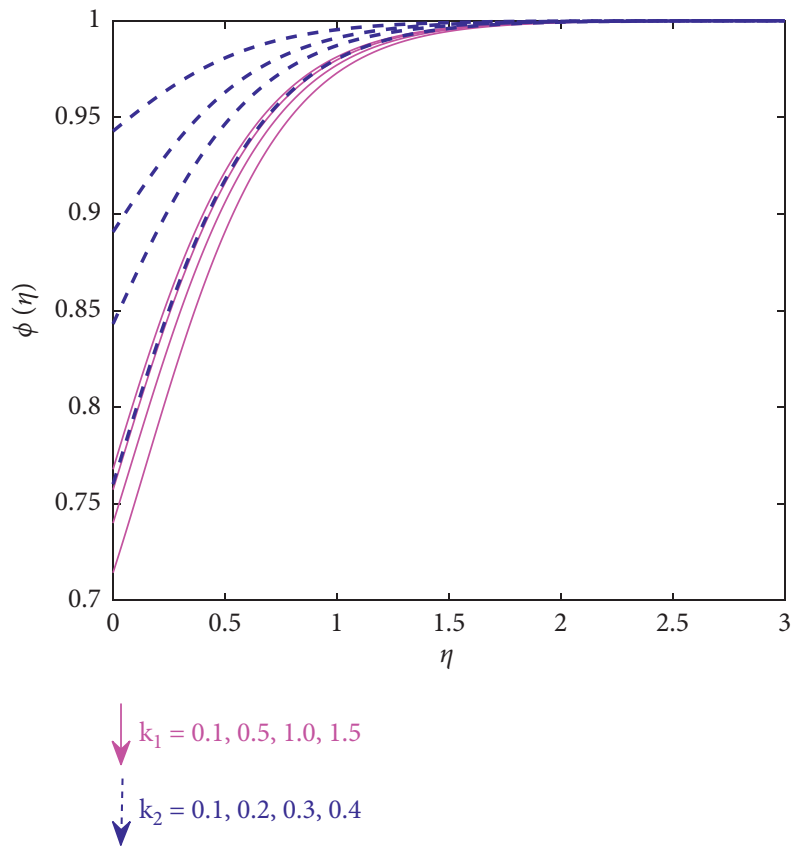

FiguRE 7: Variation of $\phi(\eta)$ versus $k_{1}$ and $k_{2}$.

by envying the solutal distribution. Stronger strength of homogeneous response $\left(k_{1}\right)$ and strength of heterogeneous reaction constant are depicted. During the homogeneous process, the reactants will be utilized, and concentration deteriorates the viscosity. Strength of homogeneous reactions will be increased by the solutal profile. Khan et al. [27] and Ahmed et al. [28] described the profile of obtained results. 


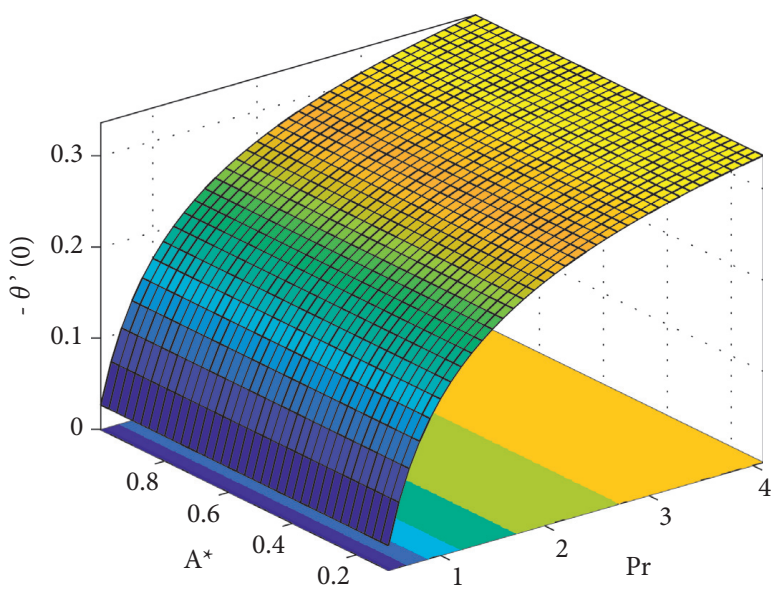

(a)

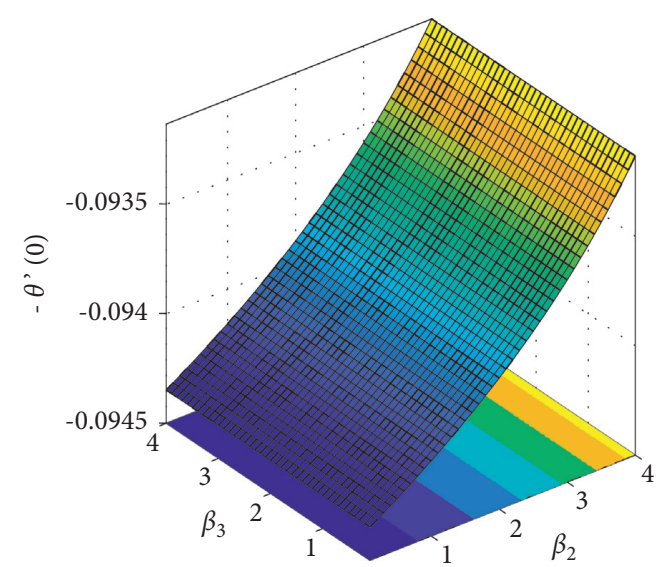

(b)

Figure 8: (a) Variation of $-\theta^{\prime}(0)$ versus $A^{*}$ and Pr. (b) Variation of $-\theta^{\prime}(0)$ versus $\beta_{2}$ and $\beta_{3}$.

The stimulus of space-related heat source parameter $\left(A^{*}\right)$ and the Prandtl number $(\operatorname{Pr})$ against the heat transfer rate of Burgers' liquid is delineated in Figure 8(a). Prandtl number is used for heat transfer rate, and this is dependent on Burgers' fluid. $\beta_{2}$ on heat transfer rate versus $\beta_{3}$ is influenced from Figure 8(b). Heat transfer rate is enhanced by reducing the parameter of Burgers' fluid which consists of higher estimation and a rise in values of $\beta_{3}$.

\section{Concluding Remarks}

A theoretical analysis for incompressible two-dimensional magnetized Burgers' fluid in accordance with the space- and temperature-dependent heat generation phenomenon induced by a convectively heated stretching cylinder is performed. RKF-45 method is employed by the ODEs disclosed by the physical outcomes. In these investigations, the main findings are given in the following:

(1) Magnetic force parameter, time relaxation parameter, and parameter of material for Burgers' fluid will be intensified by identifying the motion of Burgers' fluid. Here, the curvature parameter and velocity ratio parameter scale are detected by the escalation.

(2) To improve the retardation time constant and Prandtl number the of Burgers magneto fluid is studied based on the thermal thickness of the layers and diminution behavior of thermal contours.

(3) Biot number, space, and temperature will be enhanced by Burgers' liquid of temperature distribution. This will depend on the time constant of relaxation, fluid parameter of Burgers, and source parameter of heat dependence.

(4) Curvature parameter and retardation time constant are varied by boosting Burgers' fluid in the boundary layer. This is the combination of solutal thickness and concentration rate of the boundary layer.
(5) Higher Prandtl numbers are predicted with stronger magnitude based on the solutal profile.

(6) Biot number will reduce the higher values of Burgers' liquid by depicting the heat transfer rate. Similarly, higher Prandtl numbers are obtained to increase the trend.

The current study clearly demonstrated the potential significance of rheological models. Nanofluid model study is ignored in the present generation. By using porous materials, this work can be extended in future [62].

\section{Data Availability}

No data were used to support this study.

\section{Conflicts of Interest}

The authors declare that they have no conflicts of interest.

\section{References}

[1] R. Y. Dong, Y. Dong, and A. Sellitto, "An analogy analysis between one-dimensional non-Fourier heat conduction and non-Newtonian flow in nanosystems," International Journal of Heat and Mass Transfer, vol. 164, Article ID 120519, 2021.

[2] S. A. M. Mehryan, M. Vaezi, M. Sheremet, and M. Ghalambaz, "Melting heat transfer of power - law non-Newtonian phase change nano-enhanced n-octadecane-mesoporous silica $\left(\mathrm{MPSiO}_{2}\right)$," International Journal of Heat and Mass Transfer, vol. 151, Article ID 119385, 2020.

[3] N. Hazeri-Mahmel, Y. Shekari, and A. Tayebi, "Three-dimensional analysis of forced convection of Newtonian and non-Newtonian nanofluids through a horizontal pipe using single-and two-phase models," International Communications in Heat and Mass Transfer.vol. 121, Article ID 105119, 2021.

[4] W. Ajeeb, M. S. A. Oliveira, N. Martins, and S. M. Sohel Murshed, "Forced convection heat transfer of non-Newtonian MWCNTs nanofluids in microchannels under laminar flow," International Communications in Heat and Mass Transfer.vol. 127, Article ID 105495, 2021. 
[5] P. K. Yadav and A. Kumar, "An inclined magnetic field effect in entropy production of non-miscible Newtonian and micropolar fluid in a rectangular conduit," International Communications in Heat and Mass Transfer.vol. 124, Article ID 105266, 2021.

[6] M. H. Esfe, S. Esfandeh, M. H. Kamyab, and D. Toghraie, "Analysis of rheological behaviour of MWCNT-Al2O3 (10: 90)/5W50 hybrid non-Newtonian nanofluid with considering viscosity as a three-variable function," Journal of Molecular Liquids, vol. 341, Article ID 117375, 2021.

[7] A. Saleem, A. Qaiser, S. Nadeem, M. Ghalambaz, and A. Issakhov, "Physiological flow of non-Newtonian fluid with variable density inside a ciliated symmetric channel having compliant wall," Arabian Journal for Science and Engineering, vol. 46, no. 1, pp. 801-812, 2021.

[8] G. Vishal, J. Tomar, and R. P. Bharti, "Critical parameters for non-Newtonian shear-thickening power-law fluids flow across a channel confined circular cylinder," Journal of the Taiwan Institute of Chemical Engineers, vol. 123, pp. 34-46, 2021.

[9] B. Ali, C. S. K. Raju, L. Ali, S. Hussain, and T. Kamran, "GJitter impact on magnetohydrodynamic non-Newtonian fluid over an inclined surface: finite element simulation," Chinese Journal of Physics, vol. 71, pp. 479-491, 2021.

[10] M. Subhas Abel, J. V. Tawade, and M. M. Nandeppanavar, "MHD flow and heat transfer for the upper-convected Maxwell fluid over a stretching sheet," Meccanica, vol. 47, no. 2, pp. 385-393, 2012.

[11] M. Waqas, M. Ijaz Khan, T. Hayat, and A. Alsaedi, "Stratified flow of an Oldroyd-B nanoliquid with heat generation," Results in Physics, vol. 7, pp. 2489-2496, 2017.

[12] J. M. Burgers, Mechanical Considerations-Model SystemsPhenomenological Theories of Relaxation and of Viscosity, Nordemann Publishing Company, New York, US, 1939.

[13] J. C. Maxwell, "On the dynamical theory of gases," Philosophical Transactions of the Royal Society of London, vol. 157, pp. 26-78, 1866.

[14] T. Hayat, S. Ali, M. Awais, and M. S. Alhuthali, "Newtonian heating in stagnation point flow of Burgers fluid," Applied Mathematics and Mechanics, vol. 36, no. 1, pp. 61-68, 2015.

[15] M. Waqas, T. Hayat, M. Farooq, S. A. Shehzad, and A. Alsaedi, "Cattaneo-Christov heat flux model for flow of variable thermal conductivity generalized Burgers fluid," Journal of Molecular Liquids, vol. 220, pp. 642-648, 2016.

[16] T. Hayat, M. Waqas, S. A. Shehzad, and A. Alsaedi, "On model of Burgers fluid subject to magneto nanoparticles and convective conditions," Journal of Molecular Liquids, vol. 222, pp. 181-187, 2016.

[17] M. Khan, Z. Iqbal, and A. Ahmed, "Stagnation point flow of magnetized Burgers' nanofluid subject to thermal radiation," Applied Nanoscience, vol. 10, no. 12, pp. 5233-5246, 2020.

[18] S. A. Shehzad, T. Hayat, and A. Alsaedi, "Influence of convective heat and mass conditions in MHD flow of nanofluid," Bulletin of the Polish Academy of Sciences, Technical Sciences, vol. 63, no. 2, pp. 465-474, 2015.

[19] W. Zuo, J. Li, Y. Zhang, Q. Li, S. Jia, and Z. He, "Multi-factor impact mechanism on combustion efficiency of a hydrogenfueled micro-cylindrical combustor," International Journal of Hydrogen Energy, vol. 45, no. 3, pp. 2319-2330, 2020.

[20] K. Madhavi, V. R. Prasad, and S. A. Gaffar, "Darcy flow of polymer from an inclined plane with convective heat transfer analysis: a numerical study," Journal of Thermal Analysis and Calorimetry, vol. 146, no. 1, pp. 117-129, 2021.
[21] N. S. Shashikumar, M. Madhu, S. Sindhu, B. J. Gireesha, and N. Kishan, "Thermal analysis of MHD Williamson fluid flow through a microchannel," International Communications in Heat and Mass Transfer, vol. 127, Article ID 105582, 2021.

[22] M. V. S. Rao, K. Gangadhar, A. J. Chamkha, and P. Surekha, "Bioconvection in a convectional nanofluid flow containing gyrotactic microorganisms over an isothermal vertical cone embedded in a porous surface with chemical reactive species," Arabian Journal for Science and Engineering, vol. 46, no. 3, pp. 2493-2503, 2021.

[23] K. Gangadhar, R. Edukondala Nayak, M. Venkata Subba Rao, and T. Kannan, "Nodal/saddle stagnation point slip flow of an aqueous convectional magnesium oxide-gold hybrid nanofluid with viscous dissipation," Arabian Journal for Science and Engineering, vol. 46, no. 3, pp. 2701-2710, 2021.

[24] M. Ahmad, F. Mabood, S. A. Shehzad, M. Taj, and F. Mehmood, "Convective heat and zero-mass flux conditions in the time-dependent second-grade nanofluid flow by unsteady bidirectional surface movement," Chinese Journal of Physics, vol. 72, pp. 448-460, 2021.

[25] M. A. Chaudhary and J. H. Merkin, "A simple isothermal model for homogeneous-heterogeneous reactions in boundary-layer flow. I equal diffusivities," Fluid Dynamics Research, vol. 16, no. 6, pp. 311-333, 1995.

[26] J. H. Merkin, "A model for isothermal homogeneous-heterogeneous reactions in boundary-layer flow," Mathematical and Computer Modelling, vol. 24, no. 8, pp. 125-136, 1996.

[27] M. Khan, J. Ahmed, and W. Ali, "An improved heat conduction analysis in swirling viscoelastic fluid with homogeneous-heterogeneous reactions," Journal of Thermal Analysis and Calorimetry, vol. 143, no. 6, pp. 4095-4106, 2021.

[28] J. Ahmed, M. Khan, and L. Ahmad, "Effectiveness of homogeneous-heterogeneous reactions in Maxwell fluid flow between two spiraling disks with improved heat conduction features," Journal of Thermal Analysis and Calorimetry, vol. 139, no. 5, pp. 3185-3195, 2020.

[29] Z. Hussain, T. Hayat, A. Alsaedi, and I. Ullah, "On MHD convective flow of Williamson fluid with homogeneousheterogeneous reactions: a comparative study of sheet and cylinder," International Communications in Heat and Mass Transfer, vol. 120, Article ID 105060, 2021.

[30] M. Waqas, "A mathematical and computational framework for heat transfer analysis of ferromagnetic non-Newtonian liquid subjected to heterogeneous and homogeneous reactions," Journal of Magnetism and Magnetic Materials, vol. 493, Article ID 165646, 2020.

[31] S. Rashid, M. I. Khan, T. Hayat, M. Ayub, and A. Alsaedi, "Theoretical and analytical analysis of shear rheology of Oldroyd-B fluid with homogeneous-heterogeneous reactions," Applied Nanoscience, vol. 10, no. 8, pp. 3035-3043, 2020.

[32] N. Xu and H. Xu, "A modified model for isothermal homogeneous and heterogeneous reactions in the boundarylayer flow of a nanofluid," Applied Mathematics and Mechanics, vol. 41, no. 3, pp. 479-490, 2020.

[33] M. Irfan, M. Khan, and W. A. Khan, "Impact of homogeneous-heterogeneous reactions and non-Fourier heat flux theory in Oldroyd-B fluid with variable conductivity," Journal of the Brazilian Society of Mechanical Sciences and Engineering, vol. 41, no. 3, p. 135, 2019.

[34] C. Y. Wang, "Fluid flow due to a stretching cylinder," Physics of Fluids, vol. 31, no. 3, pp. 466-468, 1988. 
[35] C. Y. Wang and C.-O. Ng, "Slip flow due to a stretching cylinder," International Journal of Non-linear Mechanics, vol. 46, no. 9, pp. 1191-1194, 2011.

[36] L. J. Crane, "Boundary layer flow due to a stretching cylinder," ZAMP Zeitschrift für angewandte Mathematik und Physik, vol. 26, no. 5, pp. 619-622, 1975.

[37] K. Gangadhar, D. Naga Bhargavi, M. Venkata Subba Rao, and A. J. Chamkha, "Entropy minimization on magnetized Boussinesq couple stress fluid with non-uniform heat generation," Physica Scripta, vol. 96, Article ID 095205, 2021.

[38] S. E. Ahmed and M. Alhazmi, "Impacts of the rotation and various thermal conditions of cylinders within lid-driven enclosures filled with glass balls in the presence of radiation: FEM simulation," International Communications in Heat and Mass Transfer, vol. 128, Article ID 105603, 2021.

[39] J. Luo, S.-Y. Wu, L. Xiao, and Z.-L. Chen, "Hydrodynamics and heat transfer of multiple droplets successively impacting on cylindrical surface," International Journal of Heat and Mass Transfer, vol. 180, Article ID 121749, 2021.

[40] D. Kim and D.-K. Kim, "Experimental study of natural convection from vertical cylinders with branched pin fins," International Journal of Heat and Mass Transfer, vol. 177, Article ID 121545, 2021.

[41] M. K. Triveni and R. Panua, "Natural and mixed convection study of isothermally heated cylinder in a lid-driven square enclosure filled with nanofluid," Arabian Journal for Science and Engineering, vol. 46, no. 3, pp. 2505-2525, 2021.

[42] Y.-X. Li, H. Waqas, K. Al-Khaled et al., "Simultaneous features of Wu's slip, nonlinear thermal radiation and activation energy in unsteady bio-convective flow of Maxwell nanofluid configured by a stretching cylinder," Chinese Journal of Physics, vol. 73, pp. 462-478, 2021.

[43] N. Abbas, S. Nadeem, A. Saleem, M. Y. Malik, A. Issakhov, and F. M. Alharbi, "Models base study of inclined MHD of hybrid nanofluid flow over nonlinear stretching cylinder," Chinese Journal of Physics, vol. 69, pp. 109-117, 2021.

[44] Y.-Q. Song, A. Hamid, T.-C. Sun et al., "Unsteady mixed convection flow of magneto-Williamson nanofluid due to stretched cylinder with significant non-uniform heat source/ sink features," Alexandria Engineering Journal, vol. 61, no. 1, pp. 195-206, 2022.

[45] K. G. Kumar, B. J. Gireesha, M. R. Krishnamurthy, and B. C. Prasannakumara, "Impact of convective condition on Marangoni convection flow and heat transfer in Casson nanofluid with uniform heat source sink," Journal of Nanofluids, vol. 7, no. 1, pp. 108-114, 2018.

[46] K. G. Kumar, B. J. Gireesha, G. K. Ramesh, and N. G. Rudraswamy, "Double-diffusive free convective flow of Maxwell nanofluid past a stretching sheet with nonlinear thermal radiation," Journal of Nanofluids, vol. 7, no. 3, pp. 499-508, 2018.

[47] B. J. Gireesha, K. G. Kumar, N. G. Rudraswamy, and S. Manjunatha, "Effect of viscous dissipation on three dimensional flow of a nanofluid by considering a gyrotactic microorganism in the presence of convective condition," Defect and Diffusion Forum, vol. 388, pp. 114-123, 2018.

[48] K. G. Kumar, M. G. Reddy, P. Vijaya kumari, A. Aldalbahi, M. Rahimi-Gorji, and M. Rahaman, "Application of different hybrid nanofluids in convective heat transport of Carreau fluid," Chaos, Solitons \& Fractals, vol. 141, Article ID 110350, 2020.

[49] M. G. Reddy, P. Vijayakumari, L. Krishna, K. G. Kumar, and B. C. Prasannakumara, "Convective heat transport in a heat generating MHD vertical layer saturated by a non-Newtonian nanofluid: a bidirectional study," Multidiscipline Modeling in Materials and Structures, vol. 16, no. 6, pp. 1669-1689, 2020.

[50] M. G. Reddy, P. Vijayakumari, M. V. V. N. L. Sudharani, and K. G. Kumar, "Quadratic convective heat transport of Casson nanoliquid over a contract cylinder: an unsteady case," BioNanoScience, vol. 10, no. 1, pp. 344-350, 2020.

[51] K. G. Kumar, S. Manjunatha, B. J. Gireesha, F. M. Abbasi, and S. A. Shehzad, "Numerical illustrations of 3D tangent hyperbolic liquid flow past a bidirectional moving sheet with convective heat transfer at the boundary," Heat Transfer Asian Research, vol. 48, no. 5, pp. 1899-1912, 2019.

[52] N. A. Khan and F. Sultan, "Homogeneous-heterogeneous reactions in an e fluid over a stretching sheet in a porous medium," Special Topics \& Reviews in Porous Media - An International Journal, vol. 7, no. 1, pp. 15-25, 2016.

[53] M. Sheikh and Z. Abbas, "Homogeneous-heterogeneous reactions in stagnation point flow of Casson fluid due to a stretching/shrinking sheet with uniform suction and slip effects," Ain Shams Engineering Journal, vol. 8, no. 3, pp. 467-474, 2017.

[54] N. A. Khan, F. Sultan, and N. A. Khan, "Heat and mass transfer of thermophoretic MHD flow of Powell-Eyring fluid over a vertical stretching sheet in the presence of chemical reaction and Joule heating," International Journal of Chemical Reactor Engineering, vol. 13, no. 1, pp. 37-49, 2015.

[55] N. A. Khan, F. Riaz, and F. Sultan, "Effects of chemical reaction and magnetic field on a couple stress fluid over a nonlinearly stretching sheet," The European Physical Journal Plus, vol. 129, no. 1, p. 18, 2014.

[56] M. Imtiaz, T. Hayat, A. Alsaedi, and A. Hobiny, "Homogeneous-heterogeneous reactions in MHD flow due to an unsteady curved stretching surface," Journal of Molecular Liquids, vol. 221, pp. 245-253, 2016.

[57] I. Khan, F. Ali, N. Mustapha, and S. Shafie, "Closed-form solutions for accelerated MHDflow of a generalized Burgers' fluid in a rotating frame and porous medium," Boundary Value Problems, vol. 2015, p. 8, 2015.

[58] I. Khan, F. Ali, N. Mustapha, and S. Shafie, "Transient oscillatory flows of a generalized burgers' fluid in a rotating frame," Zeitschrift für Naturforschung A, vol. 68a, no. 3, pp. 305-309, 2013.

[59] I. Khan and S. Shafie, "Rotating MHD flow of a generalized burgers' fluid over an oscillating plate embedded in a porous medium," Thermal Science, vol. 19, no. suppl. 1, pp. 183-190, 2015.

[60] M. Aisha, "Alqahtani and ilyas khan, time-dependent MHD flow of non-Newtonian generalized burgers' fluid (GBF) over a suddenly moved plate with generalized Darcy's law," Frontiers in Physiology, 2020.

[61] I. Khan, F. Ali, and S. Shafie, "Stokes' second problem for magnetohydrodynamics flow in a burgers' fluid: the cases $\gamma=$ $\lambda 2 / 4$ and $\gamma>\lambda 2 / 4$," PLoS One, vol. 8, no. 5, Article ID e61531, 2013.

[62] J. G. Oldroyd, "On the formulation of rheological equations of state," Proc R Soc Lond Ser A, vol. 200, pp. 523-591, 1950. 